\title{
Research and Practice of the Extensive Thinking in the Teaching of Material Mechanics
}

\author{
Zhang Jian \\ College of Aerospace Engineering \\ Nanjing University of Aeronautics and Astronautics \\ Nanjing, China \\ jianzhang78@126.com \\ Wang Feng \\ Institute of Civil Engineering \\ Tongji University \\ Shanghai, China \\ wangfshh@126.com \\ Wang Dan \\ College of Aerospace Engineering \\ Nanjing University of Aeronautics and Astronautics \\ Nanjing, China \\ wangdan1001@126.com
}

\author{
Jiang Yanlong \\ College of Aerospace Engineering \\ Nanjing University of Aeronautics and Astronautics \\ Nanjing, China \\ jiang-yanlong@nuaa.edu.cn
}

\author{
Ye Xin \\ Chengxian College \\ Southeast University \\ Nanjing, China \\ yexinadd@163.com
}

\author{
Lin Jing \\ Institute of Civil Engineering \\ Tongji University \\ Shanghai, China \\ linjingseu@163.com
}

\begin{abstract}
With the integration of our country's economy and the world economy, the demand for talents in society has also undergone fundamental changes. In order to achieve the objectives of high-quality, strong-capacity, wide-caliber, and thick-based training, the traditional teaching of materials mechanics also faces new opportunities and challenges. It is necessary to introduce the teaching model of extensive thinking into the teaching practice of material mechanics, and pay attention to training of students' extensive thinking mode. It will play a good role in promoting the classroom teaching of material mechanics and help students find problems and think about them. The key to improving the quality of application-oriented undergraduate talent is to overcome the problems and develop students' independence, and learning enthusiasm.
\end{abstract}

Keywords-Material Mechanics; Extensive Thinking; Teaching High-quality

\section{INTRODUCTION}

The world's major inventions, cutting-edge technologies and major high-tech projects have their core ideas often derived from the most basic concept of material mechanics. In teaching, students' innovative thinking ability is not directly given, but is the result of gradual training and gradual development in an appropriate teaching environment. Teachers should provide and create an environment for students so that students can often use extensibility in their daily learning. Thinking to observe, analyze and solve problems, and promote the continuous improvement of students' innovative ability. Higher education should transform from a knowledge-based model to a creative one. From exam-oriented education to quality education, the material mechanics curriculum must also adapt to this development. This paper focuses on the research and practice of extensive thinking in the teaching of material mechanics, and solves the main problems: combining the characteristics of material mechanics teaching, studying the teaching mode of extensive thinking; integrating the teaching mode of extensive thinking into the teaching of material mechanics, tracking the development of disciplines, Construct and propose the problem of extensive of material mechanics; pay attention to training students' ability of extensive thinking, solve the problem of extensive thinking of material mechanics, and then inspire students' learning potential and obtain good teaching results.

Based on the existing teaching and research of material mechanics and practical teaching experience, through the study of this project, the teaching model of the extensive thinking is further deepened, the questions of the extensive thinking are constructed, and the students' ability of the extensive thinking is cultivated to cultivate the students' Scientific research capabilities lay a good foundation.

\section{THE BASIC CONCEPT OF EXTENSIVE THINKING}

The course of material mechanics is a very important technical basic course for engineering majors [1]. The course of materials mechanics not only enables students to learn the basic knowledge of mechanics, but also can train students to simplify engineering practical problems into mechanical models, which has far-reaching practical significance for 
cultivating students' engineering concepts and solving practical problems [2]. However, there are also many problems in the teaching of materials mechanics, such as many teaching contents, difficult to grasp key points, poor flexibility, and students' dullness, which can not cause students to use their brains, too much work, students are too busy to deal with, and they are not well researched [3]. The problem is not lively learning. In order to adapt to modern teaching reforms and innovations and constantly improve the teaching quality of materials mechanics, it is necessary to reform the teaching content and teaching methods of material mechanics so as to cultivate more excellent talents [4]. In order to cultivate students' abilities and qualities, teaching methods must be updated from the level of curriculum and teaching objects. During the teaching process, some students can understand what the teacher's classroom is talking about, but when they do not know where to start, they are accustomed to solving the assignments according to the problem solving steps of the examples [5]. When the assignments and examples are not the same, they feel No way to start. In this case, the teacher focuses on the analysis of the problem when he explains the example, and uses the method of reasoning to divide the problem-solving process into two steps: problem analysis and problem solving [6]. In addition, on the basis of explaining these examples, there are also consciously supplementing some practical exercises. Through the practice of these topics, students can grasp the key and difficult points of the chapters, and apply knowledge flexibly [7]. Turn knowledge into skills and skills that trigger students' interest in material mechanics learning. To cultivate students' ability of thinking in malleability, we must first cultivate students' interest in science. Because material mechanics itself is a curriculum with many and complex teaching contents, derivation and more abstract courses, students will feel boring when they learn. Therefore, students' interest in material mechanics can be aroused in the teaching process and it is very important for cultivating students' creative thinking ability [8]. In the teaching process, we pay attention to the following aspects to activate the classroom atmosphere and stimulate students' interest: Use the contradictions in material mechanics to stimulate students' curiosity and thinking. There are four basic forms of rod deformation in material mechanics: axial stretching or axial compression, shearing, twisting, and bending. These deformations are caused by external forces that cause the component to eventually fail, but the material itself has resistance. Destructive ability and resistance are contradictory. Through this contradiction, students' interest can be stimulated, and this contradiction can be resolved by learning material mechanics knowledge. Students can master various concepts and theories in this process, and students can also be improved. Our thinking skills are that students are encouraged to learn material mechanics by making structural models. In the process of making models, students can combine theory and practice, develop their own innovative abilities and hands-on skills, and can specifically understand the application of basic knowledge. For example, using bamboo skin to make a simple bridge model or building model, and load experiments to determine how much load can bear [9]. After making the model, students can also try to use materials mechanics knowledge, experiments and computer software to analyze the characteristics of the material and the force characteristics of the model. These processes are different from previous teaching methods such as problem-solving exams. Students will feel fresh and can fully inspire students' ability to think about extension.

\section{THE CORE OF APPLICATION OF EXTENSIVE THINKING}

The cultivation of extensive thinking ability as the core of science and technology creativity has become an important teaching goal of university teaching [10]. In the course of teaching research, we discovered that the task of materials mechanics as a basic technical course is not only to educate students to master basic concepts and basic theories, but also to use the learned knowledge to analyze and solve practical problems, and more importantly to cultivate students' scientific thinking ability called the innovative spirit.

Therefore, the teaching activity of the course is not only a process of imparting knowledge, but also a position to cultivate the early stage of student scientific research ability. This is exactly the same as the requirement that students should contact and participate in scientific research during the undergraduate study. Knowledge is the source of innovation, innovation ability is the sublimation of knowledge accumulation, and to complete this step, it must require students to have scientific thinking ability. Based on this understanding, in the teaching of material mechanics, under the premise of strengthening knowledge transfer and capacity development, we have focused on strengthening the scientific thinking ability and innovative spirit of engineering students [11]. Scientific thinking ability refers to the logic, sensitivity, meticulousness and rationality of students' scientific thinking. It mainly includes rational thinking ability, dialectical thinking ability, systematic thinking ability, logical thinking ability and creative thinking ability.

For this reason, we focus on cultivating students' ability of scientific thinking in the following aspects. Training of Engineering Modeling Thinking Ability: When people understand and study the actual mechanical structure, they often do not directly study the actual object called the prototype, but focus on the model for research. Therefore, the actual engineering problems need to be simplified, abstracted and extracted. Then the model is studied and discussed. The engineering language is used to describe and calculate its performance, so as to provide theoretical basis and calculation method for engineering design and manufacturing. The cultivation of integrated thinking skills: When students studied material mechanics, they felt that their content was fragmented, not systematic, and sometimes it was difficult to master. In fact, material mechanics is a comparatively systematic and complete discipline, and it is an organic unified body with deformation analysis as its core.

However, the unity here still needs to give play to the subjective initiative of teachers and students, and it needs to study the content of materials and research methods. Integration requires the development of the ability to expand thinking [12]. The cultivation of the extensive thinking mode helps students to form a comprehensive and unified mode of thinking, improve the broadness and openness of students' 
thinking, and make it easier for students to look at problems from the overall perspective. A feeling of Mr. Li Si-guang once said: "Observation, experimentation and analysis are common methods for scientific research." In the teaching of material mechanics, we always implement this idea, focusing on cultivating students' analytical and inductive capabilities. On the one hand, we can make students know that the ins and outs of theory can enable students to understand the application environment of the theory, know which engineering environments can be used, which can not be used, and avoid theoretical mechanical memory and mechanical applications, while deepening students' understanding of the physical meaning of the theory and improving their knowledge transfer. Ability to achieve the purpose is here given an example.

On the other hand, the cultivation of this thinking ability will help students solve their engineering problems independently and independently. Today, new materials, new processes, and new inventions like blowouts, the engineering problems are very different. How can we solve these problems? Not only do we need to pave the way for knowledge, but more importantly we must have a scientific, malleable way of thinking.

\section{TEACHING OF EXTENSIVE THINKING}

First, according to the experience of the teaching of materials mechanics of the project team members and to collect relevant research data, it is necessary to explore the teaching mode of the extensive thinking. According to the characteristics of the teaching model of malleable thinking, the corresponding question types of the teaching of the corresponding malleable thinking are constructed, such as restraint reaction force of the continuous beam and internal force analysis.

It is a very tedious work to draw the internal force diagram of continuous beam under the action of concentrated force, concentrated couple and uniform load. The calculation of bearing restraint reaction force is a solution to the high-order statically indeterminate problem. This problem is required for this problem. : gives a system of equations for solving continuous beam constraint reaction forces;

1. Prepare a program for solving n-dimensional linear equations;

2. Designing a technical procedure for drawing internal forces;

3. Give the parameter input interface and display the corresponding internal force diagram;

4. Writing an analysis report with procedures.

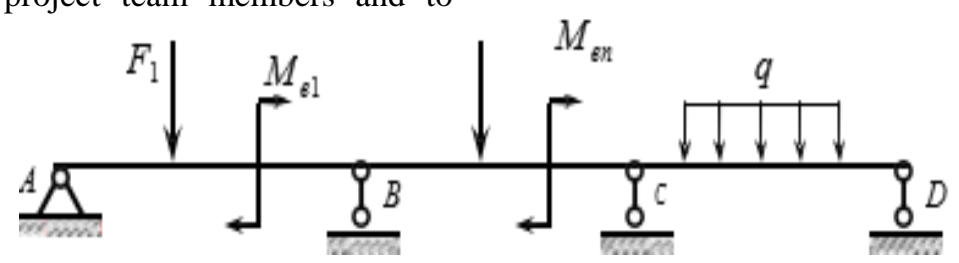

Fig. 1 The teaching of extensive thinking of continuous beam restrained reaction

For example, the deflection curve of a beam is usually performed under the premise of small deformation:

1. Experiments on deflection equation of large deflection of cantilever beam subjected to concentrated force;

2. Prepare a general procedure that can solve the problem of large deformation of cantilever beam and small deformation of cantilever beam;

3. And give the parameter input interface and display the corresponding deflection graph;

4. Contrast the difference between the large deformation problem and the small deformation problem;

5. Analyze the conditions under which small deformations can be used and the resulting errors;

6. Writing an analysis report with procedures.

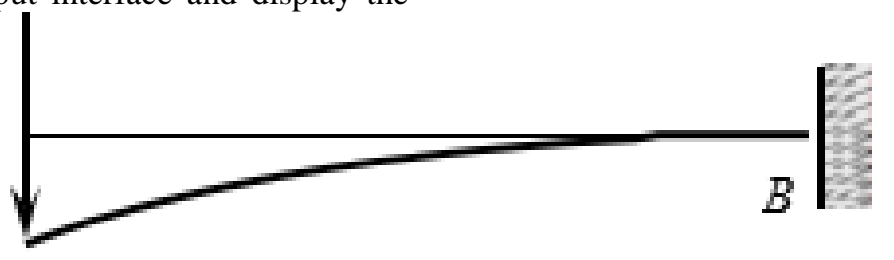

Fig. 2 The teaching of extensive thinking of the large deformation deflection curve equation

7. Using the relevant results of the teaching of the extensive thinking, the corresponding research papers and technical reports were prepared to further summarize the teaching characteristics of the extensive thinking and the supporting role of the teaching. 


\section{CONCLUSION}

In the teaching of material mechanics, under the premise of strengthening knowledge transfer and ability training, the emphasis has been placed on cultivating engineering students' scientific thinking ability and innovative spirit.

For the research and practice of extensive thinking in the teaching of material mechanics, we know that we must pay attention to the theoretical study of the teaching mode of the material mechanics extensive thinking; the application and practice of the teaching model of extensive thinking in the practical teaching of material mechanics; based on material mechanics.

The actual teaching application results continuously summarize and condense the idea of extensive thinking teaching, which makes the combination of teaching theory and practical teaching.

\section{ACKNOWLEDGMENT}

This paper is supported by National Natural Science Foundation of China (No. 11232007), Natural Science Foundation of Jiangsu Province (No. BK20130787), the Fundamental Research Funds for the Central Universities (No. NS2014003), Research Fund of Zhejiang Guangchuan Engineering Consulting Co., Ltd (No. Y1704), Research Fund of Graduate Education and Teaching Reform of NUAA(No. 2017-2), Research Fund of Education and Teaching Reform of College of Aerospace Engineering, NUAA(No. 2017-5).

\section{REFERENCES}

[1] C.C. Liu, Y.F. Shen, and Y.P. Huang, "Thinking and Practice of Cultivating Students' Scientific Thinking Ability in Material Mechanics Teaching," Higher Agricultural Education, vol. 12, pp. 65-67, October 2008.

[2] Z.Q. Long, "Thinking on Teaching Reform and Innovation of Material Mechanics Course,'Light Industry Science and Technology, vol. 18, pp. 158-159, September 2014

[3] S.Y. Ji, J.J. Wu, and Q. Li, "In the course of 'Materials Mechanics' Innovation awareness and practical ability training," Higher Science Education, vol. 7, pp. 90-92, May 2008.

[4] H.C. Quan, G.X. Fang, "Discussion on Cultivating Students' Creative Thinking Method in Material Mechanics Course," Shangxi Architecture, vol. 13, pp. 235-236, May 2016.

[5] G.H. Wu, G.P. Zou, and X.Y. Zhang, "Elementary talk on experiment teaching of material mechanics and cultivation of students' innovative consciousness," Heilongjiang Education(Higher Eduacation Research \& Appraisal), vol. 4, pp. 80-81, April 2011.

[6] F.H. Wang, F. Wei, and W.Y. Yan, “An Attempt to Cultivate Students' Innovative Ability in the Teaching of Material Mechanics and Related Courses." Experimental Technology and Management, vol.24, pp. 201202, October 2007.

[7] D.Q. Zhang, H. Zeng, and H.X. Wang, "Discussion on innovative ability training mode of full-time professional degree postgraduates," Journal of Liaoning University of Technology(Social Science Edition), vol. 18, pp. 96-100, August 2016.

[8] P. Li, L. Ma, and Y. Cai, "Innovation Ability Training System Construction of Full-time Professional Degree Graduate of Control Engineering," Journal of Jiyuan Vocational and Technical College, vol. 11, pp. 81-85, November 2012.

[9] B.K. Gao, X.F. Wang, and W.J. Ren, "Exploration on Full-time Engineering Graduates' Innovation Ability Training Mode," Guide Journal of science and education, vol. 11, pp. 61-62, April 2014.

[10] M.W. Di, D.W. Zhang, and H.Y. Liu, "Exploration and Practice of Innovative Ability Cultivation in Practice for the Full-time Professional Degree Graduate," Guangdong chemical industry, vol. 42, pp. 286-287, July 2015.

[11] Y. Qiang, "Exploration of Teaching Innovative Thinking in 'Materials Mechanics'," Three Gorges Higher Education Research, vol. 13, pp. 44 45, January 2009.

[12] Y.F. Shen, Y.Z. Xu, and L. Liu, "Combining multiple teaching methods in the teaching of material mechanics to improve students' creative thinking skills," University Education, vol. 15, pp. 146-147, April 2015. 